\title{
Mathematical Performance of American Youth: Diminished Returns of Educational Attainment of Asian-American Parents
}

\author{
Shervin Assari ${ }^{1, * \mathbb{C}}$, Shanika Boyce ${ }^{2}$, Mohsen Bazargan ${ }^{1,3}$ and Cleopatra H. Caldwell ${ }^{4,5}$ \\ 1 Departments of Family Medicine, College of Medicine, Charles R Drew University of Medicine and Science, \\ Los Angeles, CA 90059, USA \\ 2 Departments of Pediatrics, College of Medicine, Charles R Drew University of Medicine and Science, \\ Los Angeles, CA 90059, USA \\ 3 Departments of Family Medicine, University of California, Los Angeles (UCLA), Los Angeles, \\ CA 90095, USA \\ 4 Department of Health Behavior and Health Education, School of Public Health, University of Michigan, \\ Ann Arbor, MI 48109, USA \\ 5 Center for Research on Ethnicity, Culture, and Health (CRECH), School of Public Health, University of \\ Michigan, Ann Arbor, MI 48109, USA \\ * Correspondence: assari@umich.edu
}

Received: 10 January 2020; Accepted: 30 January 2020; Published: 5 February 2020

\begin{abstract}
The Marginalization-related Diminished Returns (MDR) phenomenon refers to the weaker effects of parental educational attainment for marginalized groups, particularly ethnic minorities. This literature, however, is limited to Blacks and Hispanics; thus, it is not clear if the MDR phenomenon also applies to the educational performance of Asian Americans or not. To explore ethnic differences in the association between parental educational attainment and youth mathematical performance among 10th-grade American high schoolers, this cross-sectional study used baseline data from the Education Longitudinal Study, a national survey of 10th-grade American youth. The analytical sample included a total number of 10,142 youth composed of 1460 (14.4\%) Asian-American and 8682 $(85.6 \%)$ non-Hispanic youth. The dependent variable was youth math performance (standard test score). The independent variable was parental education. Gender, both parents living in the same household, and school characteristics (\% students receiving free lunch, urban school, and public school) were the covariates. Ethnicity was the moderating variable. Linear regression was used for data analysis. Overall, parental educational attainment was positively associated with math ability (test score). We observed a statistically significant interaction between ethnicity (Asian American) and parental education attainment on the results of math test scores, indicating that the boosting effect of high parental educational attainment on youth math function is smaller for Asian-American youth than for Non-Hispanic White youth. While high parental educational attainment contributes to youth educational outcomes, this association is weaker for Asian-American youth than non-Hispanic White youth. Diminished returns (weaker effects of parental education in generating outcomes for ethnic minorities) that are previously shown for Hispanics and Blacks also apply to Asian Americans.
\end{abstract}

Keywords: math; population groups; socioeconomic position; socioeconomic status; education; youth; adolescents

\section{Introduction}

The Marginalization-related Diminished Returns (MDR) phenomenon refers to "less than expected" effects of socioeconomic status (SES) indicators, particularly educational attainment, on tangible 
developmental outcomes for members of socially marginalized groups (e.g., ethnic minorities) compared to the socially privilaged groups (e.g., non-Hispanic Whites) [1,2]. The MDR is an overlooked mechanism of ethnic differences in educational outcomes because this field has traditionally attributed the youth differences in outcomes to mean differences in SES (e.g., parental educational attainment) across ethnic groups [1,2]. The MDR framework, however, suggests that even when ethnic groups are equal in their mean SES, inequalities in outcomes emerge as a result of inequalities in the slope of translation of resources on outcomes (due to diminished return of available resources for non-Whites) [1,2].

Evidence on MDR provides an explanation for remaining inequalities that can sustain beyond the ethnic gap in SES. Due to MDR, we see worse than expected educational outcomes among Black youth that are from well-educated ethnic minority families [3-7]. For example, the educational attainment of parents has shown weaker effects on enhancing youth mental health [3], school performance [4,5], school attainment [6], and school bonding [7] of Blacks and Hispanics compared to Whites. Similar patterns (i.e., diminished returns) of parental educational attainment are reported for self-rated health [3], depression [8,9], anxiety [10], obesity [11,12], asthma [13], impulse control [14], ADHD [15], health care use [16], violence [17], and smoking [17]. Thus, with no exception, parental education generates fewer tangible outcomes for youth from Hispanic and Black backgrounds, compared to White individuals. This pattern, however, is never shown for Asian Americans.

The MDR framework provides a paradigm shift for understanding developmental outcomes in youth from middle-class ethnic minorities [1,2]. A major contribution of the MDR framework is that it provides an explanation for the persistence of ethnic disparities over decades despite decades of investment made to eliminate inequalities [18-20]. MDR also provides an answer to the question of why programs such as Head Start have had disappointing results in closing the achievement gaps across ethnic groups [1,2]. Unfortunately, despite its potential, MDR has been historically overlooked as an underlying mechanism behind the ethnic inequalities in the US.

One may argue that MDR is more relevant to Black and Hispanic than Asian-American families. In contrast to Asian Americans who outperform Whites [21], Black and Hispanic youth perform lower than non-Hispanic Whites [4,6]. Research has frequently documented an enormous school achievement gap that affects Black and Hispanic youth [22]; however, this gap is reversed for Asian Americans [23]. Poor school performance of Black and Hispanic youth is a major concern in the United States [22]. It may be more intuitive to expect MDR for Hispanic and Black youth because they are living at a relative disadvantage compared to non-Hispanic Whites [1,2,4-6,24]. Such a relative disadvantage may not exist for Asian Americans [21]. As academic achievement is an early contributor to later inequalities in life [22], and given that school achievement closely correlates with desired health, developmental, and behavioral outcomes, the elimination of ethnic disparities in school performance is among the strategic goals of US society. This is in part because these achievement gaps are believed to be the gateway to future ethnic health disparities later in life [25-29].

As ethnicity overlaps with SES indicators (e.g., parental educational attainment) [30,31] and as parental educational attainment has a strong protective influence on academic achievement of youth, researchers have been interested in decomposing the contribution of ethnicity from SES (e.g., parental educational attainment) in explaining ethnic differences in academic achievement [32-34]. The results of this line of research are, however, conflicting. While some researchers attribute ethnic disparities in achievement to ethnic inequalities in SES [35], the MDR framework, however, has recently been challenged on this traditional assumption [36-38]. Recent research findings suggest that Black-White and Hispanic-non-Hispanic achievement inequalities sustain at high SES families as well [4-6,24]. This is particularly of interest because the differential effects of parental educational attainment have been repeatedly shown across domains and outcomes [1,2]. The MDR framework suggests that at least some of the ethnic gap in achievement is due to the diminished returns of parental SES (educational attainment) rather than a lack of access to SES resources in ethnic minority families [1,2]. 
Worse developmental outcomes of Hispanic and Black youth compared to Non-Hispanic youth are historically attributed to lower SES. For example, some of the Black-White gaps in school achievement is attributed to the lower educational attainment of Black parents $[39,40]$. The common belief is that one main reason developmental youth outcomes tend to be worse for Hispanic and Black youth is lower SES in Black and Hispanic families [41]. MDR, however, goes beyond this simplistic view and explains why gaps remain when ethnic groups have similar SES, particularly parental educational attainment $[4-6,24]$.

For at least four reasons, the extent to which MDR contributes to the school performance of Asian-American youth is still unknown. First of all, all previous studies that have tested MDR have been limited to ethnic groups such as Blacks and Hispanics. [4-6,24] Second, Asian Americans are a minority group and may be a target of discrimination, prejudice, and marginalization [42]. Many Asian Americans live in ethnic enclaves [43,44]. As a result, their resources may have "less than expected effects." Third, their living conditions widely vary from that of Blacks or Hispanics. Asian-Americans' living conditions are more similar to Whites than Blacks, Hispanics, and other economically disadvantaged ethnic minority groups. For example, the average income and the job prestige of Asian Americans are higher than Whites [21], so on average, they face less financial difficulties [21]. However, there are still some groups of Asian Americans, such as Filipinos, who experience high levels of poverty and segregation [43-45]. Fourth, on average, Asian Americans do not have worse developmental outcomes compared to non-Hispanic White youth [46]. The assimilation of Asian Americans in the US is so high that some investigators have suggested that Asian Americans are becoming Whites in the US context [47]. Asian Americans are known as a model minority group that has been well accepted in the US community [48-53]. Asian Americans have secured some of the prestigious jobs and are very successful in admissions to college [21]. Fifth, Asian Americans may place a very high value on their children's education [21]. All these reasons suggest that Asian Americans make a unique ethnic group that may or may not experience diminished returns of parental economic and non-economic resources. Thus, whether or not the MDR framework also applies to Asian Americans remains a dilemma.

The main gap in knowledge that this study aims to fill is if the MDR phenomenon also applies to Asian Americans compared to non-Hispanic White students. Building on our prior research on diminished returns of SES indicators [1,2], particularly parental education [4-6,24], and using a nationally representative study that has rich data on ethnicity and school performance [54], this study compares Asian-American and non-Hispanic White youth for the association between parental educational attainment and math test scores. We hypothesize that parental educational attainment would generate less tangible academic outcomes (i.e., math performance) for Asian-American youth than non-Hispanic White youth. As explained above, the unique contribution of the current study is that it is the first to test the MDR phenomenon on Asian-American youth.

\section{Methods}

\subsection{Design and Settings}

We performed a cross-sectional study. This was a secondary analysis of Wave 1 of the Education Longitudinal Study (ELS) study [54]. The ELS sample is representative of United States youth in the 10th grade. We consulted the STROBE Statement, a checklist specific for cross-sectional studies, to prepare this report [55]. Funded by the US Department of Education, ELS is a state-of-the-art study of educational outcomes of American youth. Although ELS has enrolled 10th graders across all ethnic groups, we only included 10,142 youth who were composed of 1460 (14.4\%) Asian-American and 8682 (85.6\%) non-Hispanic White youth. Any students with Black, Hispanic, mixed-ethnicity, or ethnicity other than non-Hispanic White or Asian American were excluded. This included individuals who were American Indians/Alaska Natives, mixed-ethnicity, missing data on ethnicity, or unknown ethnicity. We also excluded any youth who reported to have a Hispanic/Latino ethnicity. 


\subsection{Sample and Sampling}

The ELS study's youth samples in Wave 1 were enrolled in the private, public, or Catholic schools in urban, suburban, or rural settings. The ELS study used a multi-stage stratified probability sampling to recruit the participating youth. The analytical sample was 10,142 youth.

\subsection{Study Variables}

The study variables were as follows: ethnicity as the moderator, parental educational attainment as the predictor (independent variable), youth math test score as the outcome (dependent variable), and demographic data (gender, region, and number of parents living in the household) and school characteristics (\% students receiving free lunch, urban school, and public school) as the covariates. All the study variables were measured at an individual level.

Ethnicity. Ethnicity (1 Asian American versus 0 non-Hispanic White) was self-identified. Ethnicity was operationalized as a dichotomous variable.

Parental Educational Attainment. Parent educational attainment was a continuous measure ranging from 1 to 8 , with a high score indicating higher educational attainment.

Demographic Factors. Gender, region, and number of parents living in the household were demographic covariates. Number of parents present in the household was treated as a dichotomous variable ( 1 two parents living in the household, 0 one parent living in the household). Gender was 1 $=$ male $0=$ female. Region was a nominal variable: northeast, midwest, south, and west (reference category).

School characteristics. School characteristics included school urbanity (urban vs. suburban), school governance (public versus private), and \% students receiving free lunch. School urbanity (urban vs. suburban), school governance were categorical variables; however, \% students receiving free lunch was a continuous variable.

Outcome. Our dependent variable was standardized math test score, which was treated as a continuous measure (mean $=53.18 ; \mathrm{SD}=9.37$ ). This variable is frequently used as an academic outcome with a higher score indicating better school performance [56-61].

\subsection{Statistical Analysis}

We analyzed the ELS Wave 1 data using SPSS 23.0 (IBM Corporation, Armonk, NY). To analyze the ELS data, we needed to adjust for survey weights due to the multi-stage sampling design of the study (clustered stratified sampling). As we adjusted for the baseline survey weights, the results are representative of the U.S. youth population. We had a continuous outcome with a normal distribution; thus, we could perform linear regression. We did not find evidence of multicollinearity. Our model passed the requirements of homoscedasticity (e.g., random distribution of error terms). We ran four hierarchical linear regression models, two in the pooled sample that included non-Hispanic Whites and Asian Americans. The first model only included ethnicity, parental education, and covariates. Our second model also included an interaction term between educational attainment (high school and college graduation) and ethnicity. Models 3 and 4 were performed in non-Hispanic White and Asian-American youth, respectively. From our linear regression models, we reported beta (b), standard error (SE), 95\% confidence intervals $(95 \% \mathrm{CI})$, and $p$-values. $P$-values less than 0.05 were considered statistically significant.

\subsection{Ethics}

All youth who participated in the ELS study provided written assent. Parents or guardians also provided written informed consent. The institutional review board (IRB) of the Department of Education approved the ELS study protocol. Given the publicly available data, the current secondary analysis was exempted from a full review according to the rules of the National Institute of Health (NIH) as well as Charles Drew University of Medicine and Science. 


\section{Results}

Table 1 summarizes descriptive statistics for our sample. This study included 10,142 American 10th grader youth. This number was composed of 1460 (14.4\%) Asian-American and 8682 (85.6\%) non-Hispanic youth.

Table 1. Descriptive statistics in the overall sample and by race/ethnicity $(10,142)$.

\begin{tabular}{|c|c|c|c|c|c|c|}
\hline & $\begin{array}{c}\text { All } \\
N=10,142\end{array}$ & & $\begin{array}{c}\text { Non-Hispanic } \\
\text { White } \\
n=8682\end{array}$ & & $\begin{array}{c}\text { Asian } \\
\text { American } \\
n=1460\end{array}$ & \\
\hline & $\mathbf{n}$ & $\%$ & $\mathbf{n}$ & $\%$ & $\mathbf{n}$ & $\%$ \\
\hline \multicolumn{7}{|l|}{ Ethnicity } \\
\hline Non-Hispanic White & 8682 & 85.6 & 8682 & 100.0 & - & - \\
\hline Asian American & 1460 & 14.4 & - & - & 1460 & 100.0 \\
\hline \multicolumn{7}{|l|}{ Gender } \\
\hline Female & 5107 & 50.4 & 4385 & 50.5 & 722 & 49.5 \\
\hline Male & 5035 & 49.6 & 4297 & 49.5 & 738 & 50.5 \\
\hline \multicolumn{7}{|c|}{ Family Structure (Parents Marital Status) * } \\
\hline Non-Married & 3386 & 33.4 & 2943 & 33.9 & 443 & 30.3 \\
\hline Married & 6756 & 66.6 & 5739 & 66.1 & 1017 & 69.7 \\
\hline \multicolumn{7}{|l|}{ Region* } \\
\hline Northeast & 2976 & 29.3 & 2763 & 31.8 & 213 & 14.6 \\
\hline Midwest & 1977 & 19.5 & 1696 & 19.5 & 281 & 19.2 \\
\hline South & 3428 & 33.8 & 3151 & 36.3 & 277 & 19.0 \\
\hline West & 1761 & 17.4 & 1072 & 12.3 & 689 & 47.2 \\
\hline \multicolumn{7}{|l|}{ Urban School* } \\
\hline No & 5115 & 64.6 & 4386 & 67.1 & 729 & 52.9 \\
\hline Yes & 2802 & 35.4 & 2153 & 32.9 & 649 & 47.1 \\
\hline \multicolumn{7}{|l|}{ Public School* } \\
\hline No & 2542 & 25.1 & 2372 & 27.3 & 170 & 11.6 \\
\hline \multirow[t]{2}{*}{ Yes } & 7600 & 74.9 & 6310 & 72.7 & 1290 & 88.4 \\
\hline & Mean & SD & Mean & SD & Mean & SD \\
\hline Free Lunch* & 2.71 & 1.72 & 2.61 & 1.66 & 3.36 & 1.91 \\
\hline Parental Education & 4.75 & 2.05 & 4.76 & 2.00 & 4.68 & 2.30 \\
\hline Youth Math Score* & 53.18 & 9.37 & 53.06 & 9.14 & 53.87 & 10.64 \\
\hline
\end{tabular}

Table 2 present a summary of two linear regression models in the pooled sample. In Model 1, ethnicity (Asian American) and parental educational attainment were associated with better math function (outcome) $(\mathrm{b}=1.33,95 \% \mathrm{CI}=1.22-1.44)$. Model 2 showed a statistical interaction between ethnicity and parental educational attainment on youth educational outcomes $(b=-0.35$, $95 \% \mathrm{CI}=-0.59$ to -0.12 ). This interaction term suggested that the boosting effect of high parental educational attainment on youth math grades is significantly smaller for Asian Americans than for Non-Hispanic White youth.

In Model 1, other significant predictors of math performance included Asian-American ethnicity $(b=1.48,95 \% C I=0.90-2.06)$, male gender $(b=1.15,95 \% C I=0.75-1.55)$, presence of two parents in the household $(b=1.91,95 \% C I=1.47-2.34)$, and \% free lunch $(b=-0.83,95 \% C I=-0.98$ to -0.69$)$.

Table 3 presents the summary of two linear regression models in each ethnic group. In Model 1 (Non-Hispanic Whites), and Model 2 (Asian Americans), parental education was associated with better math function (outcome). The magnitude of the boosting effect of high parental educational attainment on youth math grade was larger for Non-Hispanic White $(b=1.33,95 \% \mathrm{CI}=1.22-1.44)$ than Asian-American ( $b=0.82,95 \% \mathrm{CI}=0.57-1.08$ ) youth. 
Table 2. Summary of two linear regressions on the interactive effects of ethnicity and parental educational attainment on math score.

\begin{tabular}{|c|c|c|c|c|c|c|c|c|c|c|c|c|c|c|}
\hline \multirow[b]{3}{*}{$\begin{array}{l}\text { Ethnicity (Asian } \\
\text { American) }\end{array}$} & \multicolumn{7}{|c|}{ Model 1 (Main Effects) } & \multicolumn{7}{|c|}{ Model 2 (Interaction Effects) } \\
\hline & \multirow{2}{*}{$\begin{array}{l}\text { Beta } \\
0.06\end{array}$} & \multirow{2}{*}{$\begin{array}{c}\mathbf{b} \\
1.48\end{array}$} & \multirow{2}{*}{$\begin{array}{c}\text { SE } \\
0.30\end{array}$} & \multicolumn{2}{|c|}{$95 \%$ CI } & \multirow{2}{*}{$\begin{array}{c}\mathbf{t} \\
5.03\end{array}$} & \multirow{2}{*}{$\begin{array}{c}p \\
0.000\end{array}$} & \multirow{2}{*}{$\begin{array}{l}\text { Beta } \\
0.13\end{array}$} & \multirow{2}{*}{$\frac{\mathbf{b}}{3.19}$} & \multirow{2}{*}{$\begin{array}{c}\text { SE } \\
0.66\end{array}$} & \multicolumn{2}{|c|}{$95 \% \mathrm{CI}$} & \multirow{2}{*}{$\begin{array}{c}\mathbf{t} \\
4.86\end{array}$} & \multirow{2}{*}{$\frac{p}{0.000}$} \\
\hline & & & & 0.90 & 2.06 & & & & & & 1.90 & 4.47 & & \\
\hline Gender (Male) & 0.06 & 1.15 & 0.20 & 0.75 & .55 & 5.69 & 0.000 & 0.06 & 1.15 & 0.20 & 0.75 & 1.55 & 5.69 & 0.000 \\
\hline $\begin{array}{r}\text { Parent } \\
\text { Toge } \\
\text { Reg }\end{array}$ & 0.10 & 1.91 & 0.22 & 1.47 & 2.34 & 8.64 & 0.000 & 0.09 & 1.89 & 0.22 & 1.46 & 2.32 & 8.58 & 0.000 \\
\hline Midwest & .01 & -0.15 & 32 & -0.77 & 0.47 & -0.47 & 0.637 & -0.01 & -0.13 & 0.32 & -0.75 & 0.49 & -0.40 & 0.689 \\
\hline No & & 0.08 & 0 & -0 & 0.74 & & & & 0.10 & & & & & 0.755 \\
\hline & & 0. & & & 0.8 & & 0. & & 0.29 & & & & & 0.339 \\
\hline & 1 & -0.13 & 0.23 & -0 & 0.3 & -0.58 & 0.560 & -0.01 & -0.20 & 0.23 & & 0. & -0.90 & 0.370 \\
\hline Pub & & -0.07 & 0.28 & -0.61 & 0.48 & -0.24 & 0.811 & 0.00 & -0.03 & 0.28 & & 0.52 & -0.10 & 0.922 \\
\hline Free lunc & -0.16 & -0.83 & 0.0 & -0 & -0.69 & -11.40 & 0.000 & 6 & -0.84 & 0.0 & 8 & -0.70 & -11.49 & 0.000 \\
\hline $\begin{array}{c}\text { Parental } \\
\text { Education } \\
\text { Parental }\end{array}$ & 0.27 & 1.23 & 0.05 & 1.13 & 1.33 & 23.34 & 0.000 & 0.29 & 1.31 & 0.06 & 1.19 & 1.42 & 22.13 & 0.000 \\
\hline Education $\mathrm{x}$ & - & - & - & - & - & - & - & -0.08 & -0.35 & 0.12 & -0.59 & -0.12 & -2.91 & 0.004 \\
\hline Intercept & & 47.79 & 0.50 & 46.80 & 48.77 & 95.27 & 0.000 & & 47.41 & 0.52 & 46.39 & 48.42 & 91.53 & 0.000 \\
\hline
\end{tabular}

Table 3. Summary of two linear regressions on the effect of parental educational attainment on math scores by ethnicity.

\begin{tabular}{|c|c|c|c|c|c|c|c|c|c|c|c|c|c|c|}
\hline \multirow[b]{3}{*}{ Gender (Male) } & \multicolumn{7}{|c|}{ Model 3 (non-Hispanic Whites) } & \multicolumn{7}{|c|}{ Model 4 (Asian Americans) } \\
\hline & \multirow{2}{*}{$\begin{array}{l}\text { Beta } \\
0.07\end{array}$} & \multirow{2}{*}{$\begin{array}{c}\mathbf{b} \\
1.29\end{array}$} & \multirow{2}{*}{$\begin{array}{c}\text { SE } \\
0.21\end{array}$} & \multicolumn{2}{|c|}{$95 \% \mathrm{CI}$} & \multirow{2}{*}{$\begin{array}{c}\mathbf{t} \\
6.02\end{array}$} & \multirow{2}{*}{$\begin{array}{c}p \\
0.000\end{array}$} & \multirow{2}{*}{$\begin{array}{l}\text { Beta } \\
0.02\end{array}$} & \multirow{2}{*}{$\begin{array}{c}\mathbf{b} \\
0.35\end{array}$} & \multirow{2}{*}{$\begin{array}{l}\text { SE } \\
0.57\end{array}$} & \multicolumn{2}{|c|}{$95 \% \mathrm{CI}$} & \multirow{2}{*}{$\begin{array}{c}\mathbf{t} \\
0.62\end{array}$} & \multirow{2}{*}{$\begin{array}{c}p \\
0.533\end{array}$} \\
\hline & & & & 0.87 & 1.71 & & & & & & -0.76 & 1.46 & & \\
\hline $\begin{array}{l}\text { Parents Live } \\
\text { Together } \\
\text { Region }\end{array}$ & 0.10 & 1.90 & 0.23 & 1.45 & 2.36 & 8.15 & 0.000 & 0.08 & 1.75 & 0.62 & 0.55 & 2.96 & 2.85 & 0.004 \\
\hline Midwest & 0.04 & 0.69 & 0.35 & 0.00 & 1.38 & 1.95 & 0.051 & -0.13 & -3.80 & 0.82 & -5.41 & -2.19 & -4.63 & 0.000 \\
\hline Northeast & 0.03 & 0.73 & 0.38 & -0.02 & 1.48 & 1.91 & 0.056 & -0.04 & -0.92 & 0.76 & -2.41 & 0.56 & -1.22 & 0.222 \\
\hline South & 0.03 & 0.63 & 0.35 & -0.05 & 1.31 & 1.81 & 0.071 & 0.02 & 0.51 & 0.77 & -1.00 & 2.03 & 0.66 & 0.507 \\
\hline Urban & 0.01 & 0.11 & 0.24 & -0.36 & 0.59 & 0.47 & 0.640 & -0.06 & -1.17 & 0.60 & -2.35 & 0.01 & -1.95 & 0.051 \\
\hline Public & -0.01 & -0.18 & 0.29 & -0.74 & 0.39 & -0.61 & 0.539 & 0.03 & 0.98 & 0.91 & -0.81 & 2.76 & 1.07 & 0.284 \\
\hline Free lunch (\%) & -0.13 & -0.71 & 0.08 & -0.87 & -0.55 & -8.68 & 0.000 & -0.22 & -1.19 & 0.17 & -1.52 & -0.85 & -6.91 & 0.000 \\
\hline $\begin{array}{c}\text { Parental } \\
\text { Education }\end{array}$ & 0.29 & 1.33 & 0.06 & 1.22 & 1.44 & 23 & 0.000 & 0.18 & 0.82 & 0.13 & 0.57 & 1.08 & 6.34 & 0.000 \\
\hline Intercept & & 46.36 & 0.55 & 45.29 & 47.43 & 84.63 & 0.000 & & 53.25 & 1.38 & 50.55 & 55.95 & 38.73 & 0.000 \\
\hline
\end{tabular}

Presence of two parents in the household was associated with higher math performance for non-Hispanic White $(\mathrm{b}=1.90,95 \% \mathrm{CI}=1.45-2.36)$ and Asian-American $(\mathrm{b}=1.75,95 \% \mathrm{CI}=0.55-2.96)$ youth. \% Free lunch was associated with lower math performance for non-Hispanic White $(b=-0.71$, $95 \% \mathrm{CI}=-0.87$ to -0.55$)$ and Asian-American $(\mathrm{b}=-1.19,95 \% \mathrm{CI}=-1.52$ to -0.85$)$ youth. School urbanity and governance were not associated with math performance for either non-Hispanic White or Asian-American youth.

\section{Discussion}

The current study showed that (a) overall, the high educational attainment of parents is associated with higher math performance in youth; however, (b) this boosting effect is weaker for Asian-American than for Non-Hispanic White families. That means parental education is a less salient determinant of math performance for Asian-American students compared to non-Hispanic White students.

This study shows that, similar to Hispanic and Black youth [5],the MDR phenomenon can also be seen for Asian-American youth. As these patterns are not specific to a single ethnic group, a probable cause for the MDR of parental educational attainment on youth school outcomes is upstream social forces that to, one degree or another, marginalize all ethnic minority families whether they are Black [5], Hispanic [5], or Asian American. 
In a recent paper [5], worse than expected school performance was found for Black and Hispanic youth with high parental education. The same study showed higher than expected tobacco dependence, aggression, psychological distress, and chronic diseases in Black and Hispanic youth with high parental education. Similar to other studies [62-64], a plausible conclusion is that some upstream and distal social processes, in effect, reduce the effects of parental education for non-White families [5]. Thus, the MDR phenomenon is not limited to Blacks or Hispanics as even Asian Americans (who are a privileged minority group) show a similar disadvantage.

Ethnic minority youth with highly educated parents report worse than expected outcomes across almost all domains. That means middle-class ethnic minority youth have higher health and social needs than middle-class Whites. Research has shown that risk of asthma [13], Attention Deficit Hyperactivity Disorder [15], mental health problems [3], depression [8,9], obesity [11,12], dental health problems [65], poor health care use [16], poor school outcomes [4], poor school attainment [6], poor school bonding [7], impulse control [14], and cigarette smoking [17] remain high in high SES Black and Hispanic families. These risks are all disproportionate to family SES (e.g., parental education). Similar patterns are shown for Black and Hispanic children, adults, and older adults [5,12,14,66-72]. The universal nature of these patterns suggests that some of these disparities are due to upstream underlying processes that limit the benefits of being middle class for non-Whites. Some of these upstream mechanisms may be social stratification, structural racism, and marginalization [5].

These results have considerable implications. Ethnic gaps in educational outcomes (e.g., math performance) are not all due to lower SES of ethnic minorities as middle-class ethnic minority families show worse than expected gain in outcomes due to MDR. Other social mechanisms, rather than low SES (lack of access to human and economic capital), are at work, causing gaps across ethnic groups. Ethnic minorities lag compared to non-Hispanic Whites even for the "model minority" families with the highest levels of parental education and human capital.

\subsection{Policy Implications}

In the U.S., equal access does not generate equal outcomes. That means, in the U.S., ethnic equality is not enough to produce ethnic equity. Bold and innovative policies and public health programs are needed to reduce ethnic disparities that sustain across SES levels and expand to middle-class families. Since some of the inequalities and disparities are shaped by the differential effects of SES, the type of policies that are needed must go beyond exclusively focusing on equal access and also address the broader social processes that place middle-class ethnic minority families at a relative disadvantage. As these patterns are national and systemic, there is a need for national as well as local policies that specifically equalize the return of family SES. Such policies may reduce inequalities that occur in high SES levels $[2,10,12,14,16,65,66,70,73,74]$. We need policies and program solutions that equalize the life conditions and the gains (returns) of education across ethnic groups $[75,76]$. This requires helping ethnic minority families to leverage their educational attainment $[1,2]$.

\subsection{Limitations}

There were a few methodological limitations. Due to the cross-sectional design of our study, we cannot make any causal inferences. Due to an imbalanced sample size across ethnic groups, ethnic-specific models may have differential statistical power. This study only included Asian Americans, and other studies should include Native Americans as well as immigrants. This study did not include variables on immigration status. We only studied the differential effect of parental educational attainment. Other SES indicators (e.g., wealth, income, marital status, and employment) may have a role. This study did not include any higher-level factors or details of school quality other than urbanity, governance, and \% free lunch. Educational programs of the school or educational policies of the state were not included. Such programs may be differently available for ethnic groups who reside in different neighborhoods and attend different schools. Although these limitations exist, this study still makes an important contribution to the existing literature on the MDR phenomenon 
and extends the existing knowledge from Blacks and Hispanics to Asian Americans. Some of the strengths of the current investigation included a large sample size, a random sample that results in representative and generalizable findings to the US. However, the data were collected in 2002 and newer studies are needed. This was the first study to test the MDR phenomenon on Asian Americans.

\section{Conclusions}

In the United States, Asian-American youth remain at a relative disadvantage compared to Non-Hispanic White youth regarding the magnitude of the effect of their parental education on their math performance. The observed diminished returns of parental education in terms of math performance in Asian-American youth are similar to the previous findings on African-American/Black and Hispanic/Latino youth.

Author Contributions: Conceptualization, S.A., S.B., M.B. and C.H.C.; Investigation, S.B.; Writing - original draft, S.A. and M.B.; Writing-review \& editing, S.A., S.B., M.B. and C.H.C. All authors have read and agreed to the published version of the manuscript.

Funding: This research received no external funding.

Conflicts of Interest: The authors declare no conflict of interest.

\section{References}

1. Assari, S. Health Disparities due to Diminished Return among Black Americans: Public Policy Solutions. Soc. Issues Policy Rev. 2018, 12, 112-145. [CrossRef]

2. Assari, S. Unequal Gain of Equal Resources across Racial Groups. Int. J. Health Policy Manag. 2017, 7, 1-9. [CrossRef] [PubMed]

3. Assari, S. Parental Educational Attainment and Mental Well-Being of College Students; Diminished Returns of Blacks. Brain Sci. 2018, 8, 193. [CrossRef] [PubMed]

4. Assari, S. Parental Educational Attainment and Academic Performance of American College Students; Blacks' Diminished Returns. J. Health Econ. Dev. 2019, 1, 21-31.

5. Assari, S.B.M.; Caldwell, C.H. Association Between Parental Educational Attainment and Youth Outcomes and Role of Race/Ethnicity. JAMA Netw. Open 2020, 2. [CrossRef]

6. Assari, S. Parental Education Attainment and Educational Upward Mobility; Role of Race and Gender. Behav. Sci. 2018, 8, 107. [CrossRef]

7. Assari, S. Family Socioeconomic Position at Birth and School Bonding at Age 15; Blacks' Diminished Returns. Behav. Sci. 2019, 9, 26. [CrossRef]

8. Assari, S.; Caldwell, C.H. High Risk of Depression in High-Income African American Boys. J. Racial Ethn Health Disparities 2018, 5, 808-819. [CrossRef]

9. Assari, S.; Lankarani, M.M.; Caldwell, C.H. Does Discrimination Explain High Risk of Depression among High-Income African American Men? Behav. Sci. 2018, 8, 40. [CrossRef]

10. Assari, S.; Caldwell, C.H.; Zimmerman, M.A. Family Structure and Subsequent Anxiety Symptoms; Minorities' Diminished Return. Brain Sci. 2018, 8, 97. [CrossRef]

11. Assari, S. Family Income Reduces Risk of Obesity for White but Not Black Children. Children 2018, 5, 73. [CrossRef] [PubMed]

12. Assari, S.; Thomas, A.; Caldwell, C.H.; Mincy, R.B. Blacks' Diminished Health Return of Family Structure and Socioeconomic Status; 15 Years of Follow-up of a National Urban Sample of Youth. J. Urban Health 2018, 95, 21-35. [CrossRef] [PubMed]

13. Assari, S.; Moghani Lankarani, M. Poverty Status and Childhood Asthma in White and Black Families: National Survey of Children's Health. Healthcare 2018, 6, 62. [CrossRef] [PubMed]

14. Assari, S.; Caldwell, C.H.; Mincy, R. Family Socioeconomic Status at Birth and Youth Impulsivity at Age 15; Blacks' Diminished Return. Children 2018, 5, 58. [CrossRef]

15. Assari, S.; Caldwell, C.H. Family Income at Birth and Risk of Attention Deficit Hyperactivity Disorder at Age 15: Racial Differences. Children 2019, 6, 10. [CrossRef]

16. Assari, S.; Hani, N. Household Income and Children's Unmet Dental Care Need; Blacks' Diminished Return. Dent. J. 2018, 6, 17. [CrossRef] 
17. Bachman, J.G.; O'Malley, P.M.; Johnston, L.D.; Schulenberg, J.E.; Wallace, J.M. Racial/ethnic differences in the relationship between parental education and substance use among U.S. 8th-, 10th-, and 12th-grade students: Findings from the Monitoring the Future project. J. Stud. Alcohol. Drugs 2011, 72, 279-285. [CrossRef]

18. Dankwa-Mullan, I.; Rhee, K.B.; Williams, K.; Sanchez, I.; Sy, F.S.; Stinson, N., Jr.; Ruffin, J. The science of eliminating health disparities: Summary and analysis of the NIH summit recommendations. Am. J. Public Health 2010, 100, S12-S18. [CrossRef]

19. Apter, A.J.; Casillas, A.M. Eliminating health disparities: What have we done and what do we do next? J. Allergy Clin. Immunol. 2009, 123, 1237-1239. [CrossRef]

20. Yearwood, E.L. NIH Summit: The Science of Eliminating Health Disparities. J. Child Adolesc. Psychiatr. Nurs. 2009, 22, 109-110. [CrossRef]

21. Barringer, H.R.; Takeuchi, D.T.; Xenos, P. Education, occupational prestige, and income of Asian Americans. Sociol. Educ. 1990, 63, 27-43. [CrossRef]

22. Chavous, T.M.; Rivas-Drake, D.; Smalls, C.; Griffin, T.; Cogburn, C. Gender matters, too: The influences of school racial discrimination and racial identity on academic engagement outcomes among African American adolescents. Dev. Psychol. 2008, 44, 637. [CrossRef]

23. Tran, N.; Birman, D. Questioning the model minority: Studies of Asian American academic performance. Asian Am. J. Psychol. 2010, 1, 106. [CrossRef]

24. Verlato, G.; Accordini, S.; Nguyen, G.; Marchetti, P.; Cazzoletti, L.; Ferrari, M.; Antonicelli, L.; Attena, F.; Bellisario, V.; Bono, R. Socioeconomic inequalities in smoking habits are still increasing in Italy. BMC Public Health 2014, 14, 879. [CrossRef]

25. Basch, C.E. Aggression and violence and the achievement gap among urban minority youth. J. Sch. Health 2011, 81, 619-625. [CrossRef]

26. Hair, N.L.; Hanson, J.L.; Wolfe, B.L.; Pollak, S.D. Association of Child Poverty, Brain Development, and Academic Achievement. JAMA Pediatr. 2015, 169, 822-829. [CrossRef]

27. Larson, K.; Russ, S.A.; Nelson, B.B.; Olson, L.M.; Halfon, N. Cognitive ability at kindergarten entry and socioeconomic status. Pediatrics 2015, 135, e440-e448. [CrossRef]

28. Gorey, K.M. Comprehensive School Reform: Meta-Analytic Evidence of Black-White Achievement Gap Narrowing. Educ. Policy Anal. Arch. 2009, 17, 1-17. [CrossRef]

29. Burchinal, M.; McCartney, K.; Steinberg, L.; Crosnoe, R.; Friedman, S.L.; McLoyd, V.; Pianta, R.; Network, N.E.C.C.R. Examining the Black-White achievement gap among low-income children using the NICHD study of early child care and youth development. Child Dev. 2011, 82, 1404-1420. [CrossRef]

30. Butler, A.M. Social Determinants of Health and Racial/Ethnic Disparities in Type 2 Diabetes in Youth. Curr. Diab. Rep. 2017, 17, 60. [CrossRef]

31. Carlo, G.; Crockett, L.J.; Carranza, M.A.; Martinez, M.M. Understanding ethnic/racial health disparities in youth and families in the US. Nebr. Symp. Motiv. 2011, 57, 1-11. [PubMed]

32. Rossen, L.M.; Schoendorf, K.C. Measuring health disparities: Trends in racial-ethnic and socioeconomic disparities in obesity among 2- to 18-year old youth in the United States, 2001-2010. Ann. Epidemiol. 2012, 22, 698-704. [CrossRef] [PubMed]

33. Lau, M.; Lin, H.; Flores, G. Racial/ethnic disparities in health and health care among U.S. adolescents. Health Serv. Res. 2012, 47, 2031-2059. [CrossRef] [PubMed]

34. Jones, A. Race, Socioeconomic Status, and Health during Childhood: A Longitudinal Examination of Racial/Ethnic Differences in Parental Socioeconomic Timing and Child Obesity Risk. Int. J. Environ. Res. Public Health 2018, 15, 728. [CrossRef]

35. Stull, J.C. Family socioeconomic status, parent expectations, and a child's achievement. Res. Educ. 2013, 90, 53-67. [CrossRef]

36. Navarro, V. Race or class or race and class: Growing mortality differentials in the United States. Int. J. Health Serv. 1991, 21, 229-235. [CrossRef]

37. Navarro, V. Race or class versus race and class: Mortality differentials in the United States. Lancet 1990, 336, 1238-1240. [CrossRef]

38. Navarro, V. Race or class, or race and class. Int. J. Health Serv. 1989, 19, 311-314. [CrossRef]

39. Albrecht, S.S.; Gordon-Larsen, P. Ethnic differences in body mass index trajectories from adolescence to adulthood: A focus on Hispanic and Asian subgroups in the United States. PLoS ONE 2013, 8, e72983. [CrossRef] 
40. Arellano, C.M.; Chavez, E.L.; Deffenbacher, J.L. Alcohol use and academic status among Mexican American and White non-Hispanic adolescents. Adolescence 1998, 33, 751-760.

41. Benjet, C.; Borges, G.; Medina-Mora, M.E.; Zambrano, J.; Cruz, C.; Mendez, E. Descriptive epidemiology of chronic childhood adversity in Mexican adolescents. J. Adolesc. Health 2009, 45, 483-489. [CrossRef] [PubMed]

42. Wang, L.L.-C. Meritocracy and diversity in higher education: Discrimination against Asian Americans in the post-Bakke era. Urban Rev. 1988, 20, 189-209. [CrossRef]

43. Campbell, J.R. Ethnic enclaves-Cul-de-sacs or conduits: Differential aspirations in Greek American, Caucasian American, Latino, and Asian American neighborhoods in New York City. Int. J. Educ. Res. 1994, 21, 723-738. [CrossRef]

44. Xie, Y.; Gough, M. Ethnic enclaves and the earnings of immigrants. Demography 2011, 48, $1293-1315$. [CrossRef] [PubMed]

45. Osypuk, T.L.; Diez Roux, A.V.; Hadley, C.; Kandula, N.R. Are immigrant enclaves healthy places to live? The Multi-ethnic Study of Atherosclerosis. Soc. Sci. Med. 2009, 69, 110-120. [CrossRef] [PubMed]

46. Cook, W.K.; Tseng, W. Associations of Asian Ethnicity and Parental Education with Overweight in Asian American Children and Adolescents: An Analysis of 2011-2016 National Health and Nutrition Examination Surveys. Matern. Child Health J. 2019, 23, 504-511. [CrossRef] [PubMed]

47. Zhou, M. Are asian americans becoming “white?". Contexts 2004, 3, 29-37. [CrossRef]

48. Hu, A. Asian Americans: Model minority or double minority? Amerasia J. 1989, 15, 243-257. [CrossRef]

49. Osajima, K. Asian Americans as the model minority: An analysis of the popular press image in the 1960s and 1980s. Companion Asian Am. Stud. 2005, 1, 215-225.

50. Sue, S.; Sue, D.W.; Sue, L.; Takeuchi, D.T. Psychopathology among Asian Americans: A model minority? Cult. Divers. Ment. Health 1995, 1, 39. [CrossRef]

51. Suzuki, B.H. Asian Americans as the "Model Minority": Outdoing Whites? Or Media Hype? Chang. Mag. High. Learn. 1989, 21, 13-19. [CrossRef]

52. Taylor, C.R.; Stern, B.B. Asian-Americans: Television advertising and the "model minority" stereotype. J. Advert. 1997, 26, 47-61. [CrossRef]

53. Wong, P.; Lai, C.F.; Nagasawa, R.; Lin, T. Asian Americans as a model minority: Self-perceptions and perceptions by other racial groups. Sociol. Perspect. 1998, 41, 95-118. [CrossRef]

54. NCES. Education Longitudinal Study of 2002 (ELS:2002). 2005. Available online: https://nces.ed.gov/surveys/ els2002/ (accessed on 1 February 2020).

55. Ebrahim, S.; Clarke, M. STROBE: New standards for reporting observational epidemiology, a chance to improve. Int. J. Epidemiol. 2007, 36, 946-948. [CrossRef]

56. Ding, C.S.; Song, K.; Richardson, L.I. Do mathematical gender differences continue? A longitudinal study of gender difference and excellence in mathematics performance in the US. Educ. Stud. 2006, 40, 279-295. [CrossRef]

57. Hemphill, F.C.; Vanneman, A. Achievement Gaps: How Hispanic and White Students in Public Schools Perform in Mathematics and Reading on the National Assessment of Educational Progress. Statistical Analysis Report. NCES 2011-459. Natl. Cent. Educ. Stat. 2011,1-80. Available online: https://nces.ed.gov/ nationsreportcard/pdf/studies/2011459.pdf (accessed on 1 February 2020).

58. Lee, J. College for all: Gaps between desirable and actual P-12 math achievement trajectories for college readiness. Educ. Res. 2012, 41, 43-55. [CrossRef]

59. Marsh, H.W.; Yeung, A.S. Longitudinal structural equation models of academic self-concept and achievement: Gender differences in the development of math and English constructs. Am. Educ. Res. J. 1998, 35, 705-738. [CrossRef]

60. Reardon, S.F.; Galindo, C. The Hispanic-White achievement gap in math and reading in the elementary grades. Am. Educ. Res. J. 2009, 46, 853-891. [CrossRef]

61. Safavian, N.; Conley, A. Expectancy-value beliefs of early-adolescent Hispanic and non-Hispanic youth: Predictors of mathematics achievement and enrollment. AERA Open 2016, 2, 2332858416673357. [CrossRef]

62. Mirowsky, J.; Ross, C.E. Education, Health, and the Default American Lifestyle. J. Health Soc. Behav. 2015, 56, 297-306. [CrossRef] [PubMed]

63. Ross, C.E.; Mirowsky, J. Refining the association between education and health: The effects of quantity, credential, and selectivity. Demography 1999, 36, 445-460. [CrossRef] [PubMed] 
64. Ross, C.E.; Mirowsky, J. The interaction of personal and parental education on health. Soc. Sci. Med. 2011, 72, 591-599. [CrossRef] [PubMed]

65. Assari, S. Socioeconomic Status and Self-Rated Oral Health; Diminished Return among Hispanic Whites. Dent. J. 2018, 6, 11. [CrossRef]

66. Assari, S. Blacks' Diminished Return of Education Attainment on Subjective Health; Mediating Effect of Income. Brain Sci. 2018, 8, 176. [CrossRef]

67. Assari, S. High Income Protects Whites but Not African Americans against Risk of Depression. Healthcare 2018, 6, 37. [CrossRef]

68. Assari, S. The Benefits of Higher Income in Protecting against Chronic Medical Conditions Are Smaller for African Americans than Whites. Healthcare 2018, 6, 2. [CrossRef]

69. Assari, S.; Caldwell, C.H.; Mincy, R.B. Maternal Educational Attainment at Birth Promotes Future Self-Rated Health of White but Not Black Youth: A 15-Year Cohort of a National Sample. J. Clin. Med. 2018, 7, 93. [CrossRef]

70. Assari, S.; Farokhnia, M.; Mistry, R. Education Attainment and Alcohol Binge Drinking: Diminished Returns of Hispanics in Los Angeles. Behav. Sci. 2019, 9, 9. [CrossRef]

71. Shervin, A.; Ritesh, M. Diminished Return of Employment on Ever Smoking Among Hispanic Whites in Los Angeles. Health Equity 2019, 3, 138-144. [CrossRef]

72. Assari, S. Socioeconomic Determinants of Systolic Blood Pressure; Minorities' Diminished Returns. J. Health Econ. Dev. 2019, 1, 1-11. [PubMed]

73. Assari, S.; Mistry, R. Erratum: Assari, S.; Mistry, R. Educational Attainment and Smoking Status in a National Sample of American Adults; Evidence for the Blacks' Diminished Return. Int. J. Environ. Res. Public Health 2018, 15, 2084. [CrossRef] [PubMed]

74. Assari, S.; Mistry, R. Educational Attainment and Smoking Status in a National Sample of American Adults; Evidence for the Blacks' Diminished Return. Int. J. Environ. Res. Public Health 2018, 15, 763. [CrossRef] [PubMed]

75. Grönqvist, H. Ethnic enclaves and the attainments of immigrant children. Eur. Sociol. Rev. 2006, 22, 369-382. [CrossRef]

76. Portes, A.; MacLeod, D. Educational progress of children of immigrants: The roles of class, ethnicity, and school context. Sociol. Educ. 1996, 69, 255-275. [CrossRef] 